\title{
Sentinel Lymph Node Detection In Patients With Cervical Cancer
}

\author{
Yasmina José Gutiérrez*, Laura Baquedano Mainar, Marta Lamarca Ballestero, Silvia Ortega Marcilla, Amparo \\ Borque Ibañez and Miguel Ángel Ruiz Conde
}

Department of Gynecology, Miguel Servet University Hospital, Spain

Submission: October 10, 2018; Published: January 21, 2019

*Corresponding author: Yasmina José Gutiérrez, Department of Gynecology. Miguel Servet University Hospital, Spain.

\begin{abstract}
We investigated the validity of sentinel lymph node (SLN) detection after radioactive isotope and/or blue dye injection in patients with cervical cancer. Between December 2013 and September 2018, 15 patients with cervical cancer FIGO stage I, II and II under went SLN detection during primary operation (radical laparoscopic hysterectomy) or in patients with non surgical stages to determine the condition of the nodes before radiotherapy. The detection rate of SLN was $100 \%$. The false-positive rate was $0 \%$. After the combined injection, the detection rate, especifcity, and positive predictive values were $100 \%$. A mean of 2.7 pelvic SLNs were detected. We conclude that the combination of radioactively labeled albumin with blue dye allows successful detection of SLN in patients with cervical cancer. The clinical validity of this technique must be evaluated prospectively.
\end{abstract}

Keywords: Sentinel lymph node; Cervical cáncer; Intraoperative examination; Pelvic lymphadenectomy

Abbreviations: SLN: Sentinel Lymph Node; SPSS: Statistic Process Social Sciences

\section{Introduction}

The current standard of care for women who will be diagnosed with cervical cáncer includes radical hysterectomy or trachelectomy and bilateral pelvic lymphadenectomy. For women with early-stage cervical cancer, lymph node status is the most important prognosticator of survival. However, the majority of these patients will not have lymph node metastases. For women with cervical cancer, ideally we would optimize the identification of positive lymph node spread in the minority of patients while limiting the morbidity of lymph node dissection for the majority of women who will ultimately have negative nodes. For that reason, there is significant interest in validating lymphatic mapping and sentinel node biopsy for women with this disease.

The sentinel lymph node is the first node that receives drainage from the primary tumor. Therefore, if the sentinel lymph node is negative for metastasis, the remaining lymph nodes in the nodal basin should also be free of tumor. The use of lymphatic mapping and sentinel lymph node biopsy was first described by Cabanas in 1977. In an effort to decrease complications associated with lymphadenectomy, improve detection of micrometastatic disease, and fine tune our lymphadenectomy anatomic templates, sentinel lymph node (SLN) techniques have been developed and extensively studied in many oncologic fields. As a result, SLN technique is now part of the standard treatment guidelines for the management of breast cancer, melanoma, and more recently, it is being recognized as a safe and reasonable approach in select cases of vulvar cancer $[1,2]$.

The objective of our study is Introduce sentinel lymph node detection in patients with cervical cáncer in our center and participe in the validation of the technique in a multicentric way [3].

\section{Material and Methods}

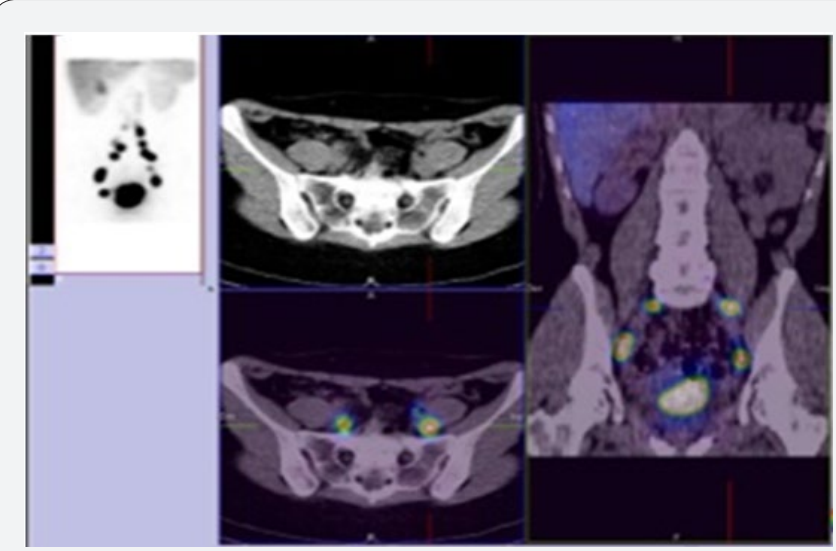

Figure 1: Images of sentinel lymph nodes obtained by nuclear medicine. 


\section{Global Journal of Reproductive Medicine}

Retrospective descriptive study of the cases of SLN in patients with cervical cáncer operated in our center from December 2013 to September 2018. We describe the procedure in our hospital, University Hospital Miguel Sevet from Zaragoza, Spain. The day before surgery $1 \mathrm{mCi} / 0,5 \mathrm{ml}$ nanocoll Technetium $99 \mathrm{~m}$ was applied into the cervix at $300,600,900$, and 1200 . Blue dye injection (Patentblue) occurred intraoperatively into the cervix at the same locations (Figures 1-2). Detector gamma probe for laparoscopy is used to perform intraoperative detection of sentynel lymph nodes (Figure 3) [4,5]. All the information about the patients and their datum were transcribed to an information base computerize. We used Statistic Process Social Sciences (SPSS) 20.0 for Windows (Copyright $@$ SPSS Inc., 2006. Licencia Universidad de Zaragoza) to statistical analyses during the study period.

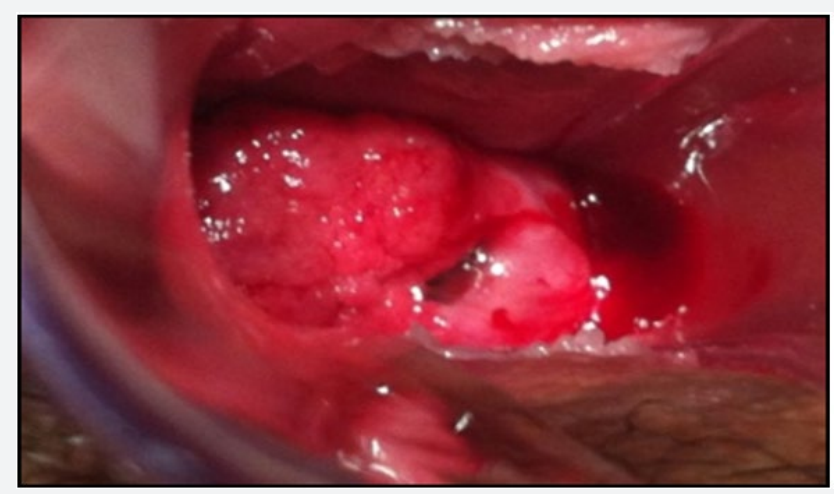

Figure 2: Cervical tumor previous intraoperatively Patentblue injection

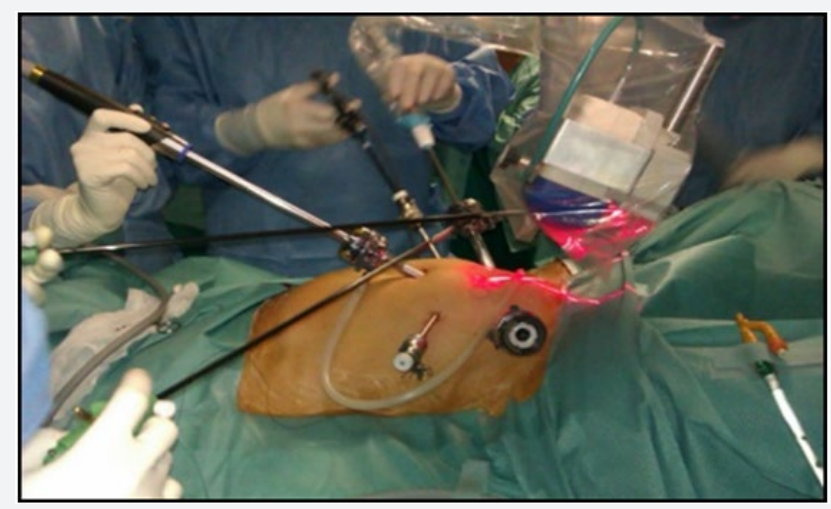

Figure 3: Detector gamma probe for laparoscopy.

Results

Between December 2013 and September 2018, 15 patients with cervical cancer FIGO stage I, II and II underwent SLN detection during primary operation (radical laparoscopic hysterectomy) or in patients with non surgical stages to determine the condition of the nodes before radiotherapy (Figure 4) [5,6]. In all cases a lymphadenectomy was also performed in the same surgical act because it was an unvalidadted technique (Figure 5). The detection rate of SLN was $100 \%$. The false-positive rate was $0 \%$. After the combined injection, the detection rate, especifcity, and positive predictive values were $100 \%$. The sensitivity was $95 \%$. There were only two false-negatives discovered. However, in one of these patients the positive node was found in a hemipelvis that did not map. A mean of 2.7 pelvic SLNs were detected [7]

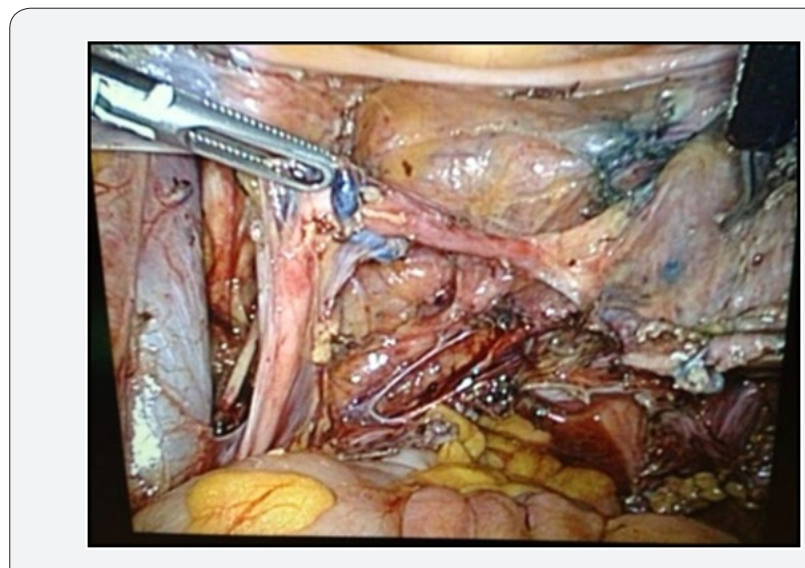

Figure 4: Intraoperative identification of sentinel lymph nodes.

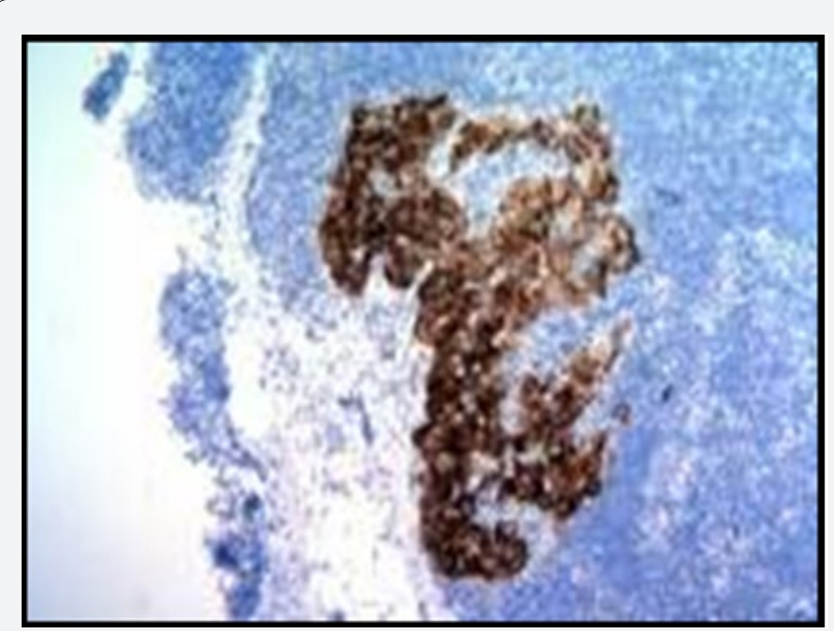

Figure 5: Anatomopathological study of sentinel lymph node.

\section{Discussion}

Multiple single institution studies have reported their experience with sentinel lymph node biopsy in cervical cancer patients. Though the type of tracer used in each of these studies is widely variable, almost all of them describe excellent negative predictive values, ranging from $88 \%-100 \%$. However, sensitivity appears to be more inconsistent. The senticol study is the largest multi-institutional trial of sentinel lymph node biopsy limited to women with early stage cervical cancer. In this study, 139 women with stage IA1 or IB1 cervical cancer underwent intracervical injection with radiocolloid and blue dye followed by sentinel node dissection and pelvic lymphadenectomy. The authors reported a detection rate of $97.8 \%$ and a sensitivity of $92 \%$. There were only 


\section{Global Journal of Reproductive Medicine}

two false-negatives discovered. The study concluded that sentinel node mapping is a sensitive method for detecting lymph node metastasis for women with early-stage cervical cancer [8].

However, opponents have voiced concern that some nodal metastases may be missed if only the sentinel lymph nodes are removed. A high sensitivity of sentinel lymph nodes (SLN) for pelvic lymph node staging has been repeatedly shown in patients with cervical cancer. However, since only SLN are evaluated by pathologic ultrastaging, the risk of small metastases, including small macrometastases and micrometastases, in non-SLN is unknown. This can be a critical limitation for the oncological safety of abandoning a pelvic lymphadenectomy. Mapping sentinel lymph nodes is popular among gynecologist- oncologists, which lead to having fewer side effects in patients who suffer from cervical cancer. Thus, more researches are required to confirm the total removal of lymph nodes in patients with sentinel lymph nodes positive [9]. The presence of an effective team (composed of an expert gynecologist- oncologist and nuclear medicine team) is an important factor to have a successful surgery with an acceptable diagnostic power, less invasive operations, and better clinical management.

\section{Conclusion}

Sentinel lymph node detection in patients with cervical cáncer is a multidisciplinary procedure involving gynecologists, pathologists and nuclear medicine. Until the validation of the techinque, lymphadenectomy will be performed in the same surgical act to all patients in order to obtain data on the reliability of the procedure. According to the previous consensus, the defined validation parameters are al least $95 \%$ of the sentinel node identification rate and false-negative rate $\leq 5 \%$. The validation of the techinque will allow to avoid morbidity to patients with early stages and to select patients with affected lymph nodes candidates for radiochemoterapy without the need for radical pelvic surgery.

\section{Acknowledgement}

To the department of pathological anatomy of the Miguel Servet University Hospital for collaborating with us.

\section{References}

1. Cibula D, Oonk MH, Abu-Rustum NR (2015) Sentinel lymph node biopsy in the manage- ment of gynecologic cancer. Curr Opin Obstet Gynecol 27(1): 66-72.

2. Tax C, Rovers MM, de Graaf C, Zusterzeel PL, Bekkers RL (2015) The sentinel node procedure in early stage cervical cancer, taking the next step; a diagnostic review. Gynecol Oncol 139(3): 559-567.

3. Bats AS, Buénerd A, Querleu D, Leblanc E, Daraï E, et al. (2011) Diagnostic value of intraoperative examination of sentinel lymph node in early cervical cancer: a prospective, multicenter study. Gynecol Oncol 123(2): 230-235.

4. Darlin L, Persson J, Bossmar T, Lindahl B, Kannisto P, et al. (2010) The sentinel node concept in early cervical cancer performs well in tumors smaller than $2 \mathrm{~cm}$. Gynecol Oncol 117(2): 266-269).

5. El-Ghobashy AE, Saidi SA (2009) Sentinel lymph node sampling in gynaecological cancers: techniques and clinical applications. EUR J Surg Oncol 35(7): 675-685).

6. Levenback C (2008) Update on sentinel lymph node biopsy in gynecologic cancers. Gynecol Oncol 111(2): 42-S43'.

7. Euscher ED, Malpica A, Atkinson EN, Levenback CF, Frumovitz M, et al. (2008) Ultra staging improves detection of metastases in sentinel lymph nodes of uterine cervix squamous cell carcinoma. Am J Surg Pathol 32(9): 1336-1343.

8. Lennox GK, Covens A (2017) Can sentinel lymph node biopsy replace pelvic lymphadenectomy for early cervical cancer? Gynecologic Oncology 144(1): 16-20.

9. Kadkhodayan S, Hasanzadeh M, Treglia G, Azad A, Yousefi Z, et al. (2015) Sentinel node biopsy for lymph nodal staging of uterine cervix cancer: a systematic review and meta-analysis of the pertinent literature. Eur J Surg Oncol 41(1): 1-20.

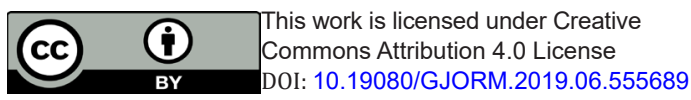

\begin{tabular}{l} 
Your next Submission with Juniper Publishers \\
will reach you the below assets \\
- Quality Editorial service \\
- Swift Peer Review \\
- Reprints availability \\
- E-prints Service \\
- Manuscript Podcast for convenient understanding \\
- Global attainment for your research \\
- Manuscript accessibility in different formats \\
( Pdf, E-pub, Full Text, Audio) \\
- Unceasing customer service \\
Track the below URL for one-step submission \\
https://juniperpublishers.com/online-submission.php \\
\hline
\end{tabular}

